\title{
HOMENS DE LETRAS NO MAGISTÉRIO: JOAQUIM MANUEL DE MACEDO E A CONSTRUÇÃO DE UMA HISTÓRIA ESCOLAR*
}

\author{
Arlette Medeiros Gasparello \\ Professora da Universidade Federal Fluminense; doutora em História da Educação \\ pela Pontifícia Universidade Católica de São Paulo
}

\section{Resumo}

O estudo tem como foco o papel instituinte e mediador de saberes exercido por professores e intelectuais brasileiros na segunda metade do século XIX e início do século XX no Rio de Janeiro. Analisa a contribuição de Joaquim Manuel de Macedo, romancista, médico e professor de História do Colégio de Pedro II na construção de uma história escolar e sua pedagogia neste período.

\section{Pallavras-chave}

Professor/autor • livro didático • história escolar.

\section{Contato}

Universidade Federal Fuminense/Campus Universitário do Gragoatá

Programa de Pós-graduação em Educação

Grupo de Pesquisa História da Educação e Ensino de História: Saberes e Práticas (GRUPHESP)

Rua V. de Rio Branco, 882

São Domingos - Niterói - Rio de Janeiro - Brasil

CEP 24210-350

E-mail: arlettemg@vm.uff.br

* A primeira versão deste artigo foi apresentada em Mesa de Comunicação Coordenada no V Congresso Brasileiro de História da Educação, ocorrido em novembro de 2008 em Aracaju/SE, promovido pela SBHE e UFS. 


\title{
MEN OF LETTERS IN EDUCATION: JOAQUIM MANUEL DE MACEDO AND THE CONSTRUCTION OF A SCHOOL HISTORY*
}

\author{
Arlette Medeiros Gasparello \\ Universidade Federal Fluminense; Ph.D. in History of Education \\ from the Pontifícia Universidade Católica de São Paulo
}

\begin{abstract}
This study has as its focal perspective the mediative and institutive role of the knowledge performed by Brazilian teachers and intellectuals in the second-half of the $19^{\text {th }}$ century and in the beginning of the $20^{\text {th }}$ century in Rio de Janeiro. It analyses the contribution of Joaquim Manuel de Macedo - novelist, physician, and History teacher at Colégio de Pedro II - in the construction of the school history and its pedagogy at that period.
\end{abstract}

\section{Keywords}

Teacher/author $\bullet$ textbook $\bullet$ school history.

\section{Contact}

Universidade Federal Fuminense/Campus Universitário do Gragoatá

Programa de Pós-graduação em Educação

Grupo de Pesquisa História da Educação e Ensino de História: Saberes e Práticas (GRUPHESP)

Rua V. de Rio Branco, 882

São Domingos - Niterói - Rio de Janeiro - Brazil

CEP 24210-350

E-mail: arlettemg@vm.uff.br

The first version of this paper was presented at the Bureau of Coordinated Communication in the V Brazilian Congress of History of Education, in November 2008 in Aracaju / SE, sponsored by the Brazilian Society of History of Education and the Federal University of Sergipe. 
Para os atores individuais ou coletivos da história, os textos que eles produzem não são apenas meios de dizer seus atos ou posições; os textos são, neles mesmos, atos e posições (Prost, 2008, p. 317).

Os livros didáticos apresentam conteúdos de diferentes campos disciplinares e seus textos podem ser fontes de estudo sobre os processos de construção de saberes associados ao mundo escolar, como as disciplinas escolares e a pedagogia vinculada a esses saberes. Esse constitui o horizonte de nossa pesquisa ${ }^{1}$ que busca perceber, nesses processos, o papel instituinte e mediador de saberes exercido por professores e intelectuais que publicavam livros e artigos na imprensa, além de exercerem o magistério nas principais instituições secundárias do Rio de Janeiro na segunda metade do século XIX e início do século XX.

A produção didática dos professores de História do Colégio de Pedro $\mathrm{II}^{2}$ teve ampla aceitação no ensino primário e secundário no Rio de Janeiro daquele período e constituiu a principal fonte deste estudo. Tais compêndios indicavam o lugar social - o Imperial Colégio de Pedro II; e a referência maior do autor - professor de História e o dos destinatários - "para uso dos alunos do Imperial Colégio".

Neste artigo discutimos a contribuição da obra didática do intelectual professor Joaquim Manuel de Macedo, médico, romancista e professor de Corografia e História do Brasil do Colégio de Pedro II no período da pesquisa. Trata-se das $\mathrm{Li}$ ções de Historia do Brazil, ${ }^{4}$ publicada em 1861, obra que deu início a uma importante fase da produção didática para o ensino secundário, a da "história imperial". 5

1 Trata-se da pesquisa "Professores e intelectuais brasileiros na construção de uma nova escola", desenvolvida no Grupo de Pesquisa História da Educação e Ensino de História: Saberes e práticas (GRUPHESP), vinculado ao Programa de Pós-Graduação em Educação da Universidade Federal Fluminense que conta com apoio da Faperj, CNPq e UFF.

2 A denominação do colégio sofreu diversas alterações: no decreto de fundação consta Colégio de Pedro II; foi usual a expressão Imperial Colégio de Pedro II. Com a República, foi nomeado Instituto Nacional de Instrução Secundária e logo depois Ginásio Nacional (1892). Em 1909, passou a ter um duplo nome: o Externato voltou a chamar-se Colégio de Pedro II e o Internato Instituto Bernardo Pereira de Vasconcelos. Em 1911, houve a reunificação dos estabelecimentos sob o antigo nome, sem a partícula "de": Colégio Pedro II, que conserva até hoje. (cf. DORIA, 1997; VECHIA; LORENZ, 1998).

3 No Brasil, o termo colégio não era desconhecido; desde os tempos da colônia os SemináriosColégios preparavam sacerdotes e letrados para os cursos superiores. O termo era também utilizado para os estabelecimentos particulares ou a cargo de religiosos. No Rio de Janeiro havia, no início do Império, os Seminários de Nossa Senhora da Lapa, o de São José e o de São Joaquim, que seria transformado no Colégio de Pedro II (Cf. ALMEIDA, 1989, LEITE, 2000).

4 Em dois volumes, o primeiro publicado em 1861, no Rio de Janeiro, pela Tipografia Imparcial, de J. M. N. Garcia, 143; o segundo em 1863, Tipografia C. A. Mello, na mesma cidade.

5 Cf. GASPARELLO (2004) que apresentou uma periodização da historiografia didática brasileira com base nos compêndios de história do Brasil publicados até 1920 em três momentos significativos: $1^{\circ}$ ) história patriótica, de 1831 a $1861 ; 2^{\circ}$ ) história imperial, de 1861 a 1900; $3^{\circ}$ ) história 
O interesse pelos processos sociais como os de mediação e invenção de saberes culturais orienta o olhar para uma especial atenção às práticas de escrita $\mathrm{e}$ experiências sociais dos sujeitos que naquele momento interferiram em mudanças e propostas para a instrução primária e a secundária. Um processo no qual os autores e seus textos são vistos como agentes instituintes da nova configuração cultural que esse período vivenciou e do qual podem ser destacados o surgimento e ampliação de novos campos de saberes, organização do ensino e formas de ensinar e aprender.

As contribuições da história cultural e da nova história intelectual inspiram a compreensão desses processos. Com Dosse (2003, p. 23), podemos perceber uma unidade de geração - uma sensibilidade comum - que parece ligar os intelectuais: "cada autor tem sua trajetória singular e inteligível em sua coerência própria. Contudo, um vínculo tácito fundamenta uma identidade comum, a do pertencimento a um espaço intelectual". Neste aspecto, Sirinelli (1996, p. 248) também analisa que as estruturas de sociabilidade do meio intelectual não seriam redutíveis a um simples mecanismo:

Todo grupo de intelectuais organiza-se também em torno de uma sensibilidade ideológica ou cultural comum e de afinidades mais difusas, mas igualmente determinantes, que fundam uma vontade e um gosto de viver.

Os que atuavam no magistério - principalmente no ensino secundário tornaram-se autores de livros didáticos, como foi usual no final do século XIX. $\mathrm{O}$ ofício de ensinar estimulou a escrita sobre os aspectos pedagógicos do ensino e sobre a educação nacional. Nessa conjuntura, ensinar nas instituições secundárias e escrever livros didáticos foram atividades intelectuais identificadas a esse conjunto de indivíduos que se destacava da massa iletrada da população. Desse modo, a tarefa de produzir livros para o ensino foi assumida como necessária e própria à função docente, o que contribuiu para o surgimento das primeiras obras didáticas da escola secundária brasileira no período imperial.

Nosso enfoque privilegia o estudo dos professores/autores a partir de suas trajetórias individuais e sociais, com especial atenção à formação, carreira docente e produção escrita de livros para o ensino. Nos referenciais da pesquisa interferem, portanto, os estudos sobre o papel do livro na configuração da cultura escolar e sua inserção na história da cultura letrada em nosso país. ${ }^{6}$ No campo da educa- 
ção, a história das disciplinas escolares na história do ensino constitui um campo relativamente novo, uma vez que permaneceu mais como estudo institucional e sociológico da escola do que sobre a definição e as modalidades de constituição e transmissão de saberes escolares, como Hery (1999) destaca.

Encontramos ainda importante fonte de reflexão no trabalho de Michel Foucault, autor que nos permite pensar a experiência histórica como um tecido complexo de práticas e saberes. Sua contribuição tem sido importante para o exame das relações discursivas em seu caráter de instituidoras de realidades sociais e históricas, bem como as questões sobre o conceito de autoria. Sem reduzir o autor a uma função, Foucault (1992, p. 46) examinou a função autor como resultado de uma série de operações específicas e complexas e que caracteriza "o modo de existência, de circulação e de funcionamento de alguns discursos no interior da sociedade".

Por outro lado, Prost (1996, p. 312) adverte que "as maneiras de falar não são inocentes; para além de sua aparente neutralidade, revelam estruturas mentais, maneiras de perceber e de organizar a realidade denominando-a". Consideramos, com este autor, que embora a aproximação dos historiadores com os estudos da linguagem acrescente maior complexidade ao tratamento histórico dos textos, orienta o olhar para como os textos dizem e não apenas sobre o que. Uma perspectiva que, associada ao nosso interesse pelos conceitos sociais ligados à educação em sua historicidade, também encaminhou nosso estudo para as contribuições de uma história conceitual proposta por Reinhart Koselleck como importante apoio teórico-metodológico. Na análise das fontes, procuramos identificar o surgimento de novos significados da mesma palavra, bem como diferenciar as expressões "conceito" e "palavra", uma vez que, se todo conceito está ligado a uma palavra, nem toda palavra representa um conceito social e político. Outro aspecto referese à necessidade de atenção à polissemia implícita nos conceitos, na medida em que, para Koselleck (2006, p. 108), "os conceitos sociais e políticos contêm uma exigência de generalização, ao mesmo tempo em que são sempre polissêmicos".

Os conceitos que se referem aos atores coletivos - os intelectuais como professores/autores - e aos processos que emergem das relações sociais, como circulação de saberes e sociabilidade foram referenciais de análise do contexto específico desta pesquisa.

Os estudos em torno das sociabilidades têm se ampliado nas últimas décadas e conquistado estatuto de legitimidade na historiografia. A palavra "sociabilidade" já era utilizada há mais tempo, porém referia-se às pessoas e grupos em sociedade, incluindo os mais diversos laços sociais, como sinônimo de socialização, de 
agrupamento, ou de civilização. Era um "tema menor, folclorizado, marginal" (Morel, 2001, p. 1). ${ }^{7}$

A cidade do Rio de Janeiro no final do século XIX já contava com um número significativo de livrarias e bibliotecas, frequentadas pela população letrada que formava o círculo de leitores. Bessone (1999, p. 27) indica que a composição desse grupo era bastante eclético:

Dele participavam jornalistas, literatos, bon vivants, flâneurs, comerciantes, políticos e boêmios, além das categorias profissionais mais afeitas aos livros, com destaque para os advogados e médicos que, além de suas tarefas específicas, tinham um trato mais íntimo com bibliotecas.

A caracterização desse grupo de intelectuais é de interesse para este estudo, que leva em conta a participação dos atores/autores intelectuais professores no processo de construção de obras didáticas para o ensino de História no Colégio de Pedro II.

A categoria socioprofissional dos professores, não revelada no levantamento de Bessone (1999), está, no entanto, representada implicitamente, devido à presença de pessoas que exerciam o magistério naquele Colégio. Numa época em que não havia instituições formadoras de professores para o ensino secundário, a função docente foi exercida por pessoas de diversas profissões e interesses, mas que possuíam uma afinidade - eram pessoas letradas e o mundo que as unia era o mundo dos livros - como escritores, jornalistas e autores de livros didáticos.

$\mathrm{Na}$ Europa, a segunda metade do século XIX foi o momento chave para a definição de uma identidade social dos intelectuais como grupo ${ }^{8}$ Escritores, críticos, historiadores, jornalistas, bibliotecários e professores, formavam redes de sociabilidade através das bibliotecas e livrarias, das associações científicas, culturais e literárias, bem como por intercâmbio de ideias na imprensa e por correspondências. ${ }^{9}$ Tais práticas sociais reforçaram alguns aspectos que foram associados à identidade do grupo, como os relacionados a certa independência

O conceito começou a ser visitado e valorizado a partir de trabalhos sobre o papel das associações para compreender a eclosão da Revolução Francesa, com Augustin Cochin (1925), trabalho que não teve repercussão imediata, mas seria recuperado por François Furet (1978). As sociabilidades - como tema e instrumental teórico e metodológico - fariam entrada definitiva no campo da pesquisa histórica acadêmica com a obra de Maurice Agulhon, um dos reconhecidos herdeiros dos Annales (cf. MOREL, 2001).

8 Sobre o tema dos intelectuais, cf. BURKE (2003); MARLETTI (1993); SIRINELLI (1996); LOPES (2003).

9 Sobre pessoas letradas, profissões liberais e elites intelectuais, ver CARVALHO (2003); BESSONE (1999). 
na realização de suas atividades e na expressão de suas posições intelectuais e políticas, como letrados e homens de saber. ${ }^{10}$

Na mesma época, no Brasil, o Rio de Janeiro também foi palco de formação de um grupo que reunia as pessoas cultas da Corte e da província, principalmente bacharéis, jurisconsultos e médicos, sendo que muitos deles exerciam o magistério secundário e superior. Além disso, esse grupo de letrados caracterizava-se por uma ativa participação na imprensa literária, em jornais e revistas, publicando artigos de crítica, poesias e ensaios e outros escritos depois editados em livros. Desse grupo saíram os professores do ensino secundário que deveriam ser, principalmente, detentores de uma cultura humanística: ser professor era ser reconhecidamente letrado. ${ }^{11}$

Os letrados tinham como principal afinidade o interesse pelo livro - que incluía sua leitura, aquisição e possível formação gradual de bibliotecas. Como "representantes ativos da cidade das letras", escolhiam lugares de convivência para encontros "relativamente informais", como livrarias, bibliotecas, cafés e jornais, para conversar e discutir sobre temas de sua preferência (Bessone, 1999, p. 19). Trocavam, entre si, frequentes correspondências, que também serviam para fortalecer as relações de amizade que, como redes de solidariedade, identificavamse mutuamente e garantiam nomeações e funções de prestígio. ${ }^{12}$

Esses intelectuais professores exerciam o magistério principalmente no Colégio de Pedro II e atuavam ainda em outras instituições como, por exemplo, Academia Militar, Mosteiro de São Bento, Faculdade de Medicina, Escola Normal da Corte, Liceu de Campos, Liceu de Artes e Ofícios e Colégio Abílio. Dentre outras instituições nas quais exerciam o magistério, contam-se a Escola Nacional de Belas Artes, a Faculdade Livre de Ciências Sociais e Jurídicas, o Ginásio Brasileiro e o Instituto Comercial.

A pluralidade de lugares de inserção social desses sujeitos na cidade letrada torna-se notória: podiam exercer suas atividades como políticos (deputados pro-

${ }^{10} \mathrm{Na}$ França, o termo intellectuel, provavelmente em uso em círculos literários e políticos, só teve sua oficialização de nascimento em 1898, no célebre Manifeste des intellectuels, tendo em vista o caso Dreyfus (MARLETTI, 1993).

${ }^{11}$ Para o estudo do tema dos intelectuais/professores e da formação da identidade do professor secundário no Brasil, cf. GASPARELLO (2005); GASPARELLO; VILLELA (2009).

${ }^{12}$ Edmundo (1938, p. 708) refere-se aos que frequentavam as livrarias no final do Império e início da República: "Vários são os grupos que na loja se formam, na hora de maior movimento, aí pelas 4, 5 e 6 da tarde. Há o grupo de Machado de Assis, com José Veríssimo, Silvio Romero Joaquim Nabuco, Rui (às vezes), Bilac, Medeiros de Albuquerque, Araripe Júnior, Rodrigo Otávio, Mário de Alencar e Clóvis Beviláqua; são os grossões da Academia que em geral, formam junto à escrivaninha do Jacintho". 
vinciais, governadores, ministros), como membros do Conselho Superior de Instrução Pública, como promotores, delegados, juízes; e ainda em cargos ou funções em instituições de ensino públicas, particulares ou religiosas. Essa diversidade de atuação configura o pertencimento desse grupo de letrados a uma rede de sociabilidades que marca sua trajetória de vida e carreira intelectual. Sociabilidades que se tornam mais visíveis entre os que ocupavam posições privilegiadas na alta administração educacional e política, bem como fortaleciam o reconhecimento social por suas atividades intelectuais, literárias ou científicas (Gasparello; Villela, 2009).

Uma característica do final do século XIX e início do XX dos intelectuais pedagogos, políticos e professores foi o interesse pela instrução pública e a necessidade de uma formação específica para o exercício da docência. Novas ideias e experiências pedagógicas de outros países como a França, Alemanha e Estados Unidos foram conhecidas a partir de viagens e a publicação de traduções de textos sobre instrução e formação de professores em jornais, revistas e livros, que intensificaram as discussões sobre o tema. (Gasparello; Villela, 2006).

A longa duração do Império comportou uma mudança na composição da elite intelectual, política e burocrática. Até 1850 se a maioria dos membros da elite foi educada em Coimbra, ${ }^{13}$ na segunda metade do século houve uma nacionalização nessa formação, com a criação dos cursos superiores no Império. Desse aspecto resultou a formação de duas gerações distintas de intelectuais e políticos: uma formada em Portugal (Coimbra), que predominou na fase de consolidação política do sistema imperial, e outra formada no Brasil (Olinda, e depois Recife). Após 1850, houve uma substituição pela geração brasileira e uma mudança na natureza dos problemas políticos que passaram a desafiar a elite.

José Murilo de Carvalho (2003, p. 37) observou que "essa transposição de um grupo dirigente teve talvez maior importância que a transposição da própria Corte portuguesa e foi fenômeno único na América". Este autor analisou os traços comuns a uma elite política e intelectual brasileira do século XIX e que serviram para garantir sucesso na tarefa de formação do Estado: "uma elite homogênea possui um projeto comum e age de modo coeso" (2003, p. 37). Esses traços comuns resultaram de um conjunto de aspectos, dentre os quais Carvalho (2003) chama a atenção para os que se referem à socialização, ao treinamento e à carreira .

${ }^{13}$ Além da Universidade de Coimbra, duas outras instituições de ensino foram importantes na formação da elite intelectual brasileira: a Real Academia de Marinha e o Colégio dos Nobres. A finalidade do Colégio era fornecer aos filhos da nobreza uma alternativa para o serviço do Estado que não fossem as carreiras eclesiástica e judiciária (Cf. CARVALHO, 2003). 
A educação - e a educação superior -, além de constituir um importante fator de aglutinação e de homogeneidade ideológica, conferia uma identidade e uma diferença ao grupo de letrados, uma vez que quase toda a elite possuía estudos superiores. O abismo entre essa elite e o grosso da população em termos educacionais era notório, na medida em que era baixíssimo o índice de população alfabetizada. Na década de 1870 , apenas $18,36 \%$ da população livre eram alfabetizados, sendo que $23 \%$ homens e $13 \%$ mulheres e, até 1920 , os analfabetos representavam $76 \%$ da população total: "era uma ilha de letrados num mar de analfabetos" (Carvalho, 2003, p. 65).

Outro aspecto da educação como marca distintiva da elite na segunda metade do século XIX era o seu caráter de cultura humanística e de base retórica. A educação superior se concentrava na formação jurídica, o que contribuía para os traços comuns de uniformização e caracterizava um grupo homogêneo em conhecimentos e habilidades:

A concentração temática e geográfica promovia contatos pessoais entre estudantes das várias capitanias e províncias e incutia neles uma ideologia homogênea dentro do espírito de controle a que as escolas superiores eram submetidas pelos governos tanto de Portugal como do Brasil (Carvalho, 2003, p. 65).

O treinamento e a carreira completavam-se na burocracia. Segundo Machado Neto em Estrutura social da República das letras, citado por Carvalho (2003, p. 61), em amostragem de 60 intelectuais que viveram entre 1870 e 1930, 80\% eram funcionários públicos, inclusive os filhos de famílias ricas. Eram funcionários os principais romancistas do Império, como Machado de Assis, José de Alencar, Raul Pompeia, assim como o poeta Gonçalves Dias, também professor do Colégio de Pedro II.

Em relação ao ensino secundário, sua instituição como curso regular com programa de estudos e número de anos definidos para sua conclusão foi oficializada a partir da fundação do Colégio de Pedro II na Corte do Rio de Janeiro em 1837, segundo o modelo de ensino literário e humanístico. Até o final do século, passou por várias reformas de instrução pública promovidas pelos ministros do Império, que buscavam organizar e controlar o ensino secundário no país, tomando por modelo aquela instituição oficial. Especial atenção foi dada pelo governo ao funcionamento do Colégio, que incluía uma série de dispositivos e normas em seus estatutos e plano de estudos. 
Desde o início de seu funcionamento, os estudos históricos fizeram parte do seu currículo ${ }^{14}$ escolar. Nesse período, iniciou-se a constituição da forma escolar do conhecimento histórico no secundário, processo que articulou as práticas ligadas ao movimento interno do Colégio, com a atuação de alunos e professores - como as aulas, os programas de ensino, os compêndios.

Os planos de estudos, os programas e os livros didáticos são apenas alguns dos elementos que dão visibilidade à tessitura interna desse campo de estudo escolar que teve como referenciais os conhecimentos históricos e geográficos de sua época. ${ }^{15}$

Escolhidos pelo poder central nos primeiros anos, os professores catedráticos passaram, em meados do século XIX, a serem selecionados por concurso público que, associado aos procedimentos, direitos e prerrogativas de sua função, envolveu a figura do mestre da instituição secundária oficial de uma aura de prestígio e honrarias. ${ }^{16}$

Esse grupo seleto atuava nas principais instituições educacionais públicas e particulares. Como intelectuais, compartilhavam, com outros letrados, espaços de convivência que criavam estruturas de sociabilidade e redes de solidariedade comuns. Sociabilidades que reforçavam uma identidade de grupo, como as que se desenvolviam em associações ou instituições culturais e científicas: o Instituto Histórico e Geográfico Brasileiro, a Academia Brasileira de Letras e outras.

Projetada no interior de um ensino de caráter humanístico, a cadeira ${ }^{17}$ de História Universal, abrangia estudos de Geografia e História Antiga, Geografia e História Média e Moderna, História Contemporânea e História do Brasil. Os assuntos eram distribuídos entre os sete anos do curso.

O estudo de Corografia e História do Brasil, até então pertencente à cadeira de História Universal, obteve uma cadeira em separado desde meados do século

${ }^{14}$ O termo "currículo" não aparece nos textos consultados. Aqui é utilizado no sentido que indicou Hamilton (1992, p. 43): "falar de um 'curriculum' pós-Reforma é apontar para uma entidade educacional que exibe tanto a globalidade estrutural quanto completude sequencial. Um "curriculum" deveria não apenas ser 'seguido'; deveria, também, ser 'completado'. A história do secundário no Brasil foi, em grande parte, a história da instituição desse estudo como 'curriculum' (Sobre as contribuições nesse campo, ver ainda GOODSON, 1995; FORQUIN, 1993).

${ }^{15}$ A História, como disciplina escolar, foi construindo também sua identidade separando-se do ensino de Geografia, que pertencia à cadeira, mas em situação subalterna. Durante muito tempo os conhecimentos geográficos limitavam-se aos aspectos físicos e políticos com o apoio de mapas, principalmente o Atlas de Delamarche (GASPARELLO, 2004).

${ }^{16}$ Para a história do Colégio Pedro II e o ensino secundário, cf. Annuario (1911); SILVA (1959; 1969); HAIDAR (1972), ANDRADE (1999), GASPARELLO (2004).

${ }^{17} \mathrm{O}$ termo foi utilizado para designar uma especialidade dos estudos a ser ministrada pelo respectivo professor - o catedrático - no Colégio e institutos superiores (GASPARELLO, 2004). 
XIX. A criação da cadeira significou ter um professor especialmente designado para a docência, um titular "catedrático" responsável pela proposição de mudanças na programação junto ao conselho de professores (mais tarde transformada em Congregação) e outros privilégios.

O primeiro a lecionar a Corografia e História do Brasil como cadeira autônoma foi o poeta e professor de Latim Gonçalves Dias, mas foi Macedo o primeiro designado para titular da cadeira em caráter permanente. Escritor e político, Macedo é celebrado como o primeiro historiador do Colégio. Foi também o primeiro professor de História que publicou um livro didático ${ }^{18}$ de história do Brasil especialmente dedicado aos alunos dessa instituição.

\section{Joaquim Manuel de Macedo: médico, intelectual, romancista, professor, polí- tico e autor de livro didático}

Joaquim Manuel de Macedo se constituiu historicamente no pertencimento a cada uma dessas categorias sociais. Nessa pluralidade de funções, construiu sua identidade marcada por um tempo de construção: o século XIX brasileiro, tempo do nascimento político do nosso Estado nação e da invenção de nossa brasilidade. Macedo participou ativamente desse tempo de fundações e invenções, no qual se destacou. Na fundação do Romantismo no Brasil, no campo das letras, tornou-se romancista reconhecido. No magistério, destacou-se na elaboração de uma história do Brasil para o ensino e na instituição das primeiras preocupações pedagógicas em livro didático para o ensino secundário.

Macedo nasceu em Itaboraí, província do Rio de Janeiro (1820-1882). Formou-se em Medicina pela Faculdade do Rio de Janeiro e foi professor de Corografia e História do Brasil no Colégio de Pedro II. Em seus aspectos biográficos, os autores consultados destacam seu papel nas letras e no magistério, tendo publicado cerca de 60 volumes entre romances, teatro, poesias, obras didáticas e históricas, incluindo algumas publicações póstumas, como assinalou Blake (1970, p. 183-184):

Foi um dos brasileiros que mais enriqueceram as letras pátrias e como romancista, dramaturgo, poeta e historiógrafo, seu nome era aplaudido em todo o Império, no primeiro

${ }^{18} \mathrm{O}$ termo livro didático tornou-se usual no Brasil desde o início do século XX, mas, na época, o termo mais utilizado foi compêndio (GASPARELLO, 2004). 
gênero principalmente, porque ele foi o fundador do romance brasileiro, sendo ainda estudante, quando publicou $A$ moreninha.

Andrade (1999, p 225) no seu estudo sobre o Colégio Pedro II, ressalta:

No magistério, o dr. Macedo destacou-se como austero professor das princesas d. Isabel e d. Leopoldina, irmãs do imperador, e como sisudo catedrático de História e Corografia do Brasil do Colégio Pedro II, cadeira que assumiu em 1858.

Macedo foi membro do Conselho Diretor da Instrução Pública da Corte, sócio fundador, $1^{\mathrm{o}}$ vice-presidente e orador do Instituto Histórico e Geográfico Brasileiro (IHGB). Integrou a Sociedade Auxiliadora da Indústria Nacional e obteve os títulos de comendador da Ordem da Rosa e da de Cristo. Estes cargos, funções e honrarias atestam a vinculação estreita entre os professores do prestigiado Colégio e a proximidade com os círculos do poder político e cultural da época.

Na política, foi militante do Partido Liberal, com mandatos de deputado provincial $(1850,1853,1854-59)$ e deputado geral (1864-68 e 1873-81). Sua rede de sociabilidades incluía ainda o pertencimento às principais instituições acadêmicas da Corte, como o já citado Instituto Histórico e Geográfico Brasileiro (desde 1845). Em 1849, fundou, com Araújo Porto-Alegre e Gonçalves Dias, a revista Guanabara. ${ }^{19}$ Seu perfil configura-se, portanto, como intelectual do mundo das letras e dos livros, com participação ativa nas principais instâncias de poder cultural e político que conferiam status e prestígio a seus membros.

Considerado um dos fundadores do romance brasileiro, foi reconhecido em vida como uma das maiores figuras da literatura contemporânea e, até o êxito de José de Alencar, o principal romancista.

Ramos (2004) acentua a capacidade de trabalho intelectual de Joaquim Manuel de Macedo:

Publicista incansável, Macedo colaborava em vários jornais cariocas e fluminenses, polemizando com vários intelectuais. Um dos embates jornalísticos mais significativos ocorreu a partir de 4 de fevereiro de 1860, data em que o romancista Bernardo Guimarães (autor do célebre romance $A$ escrava Isaura) iniciou a publicação de uma serie de artigos no jornal A Atualidade, do Rio de Janeiro, criticando o mérito literário do poema "A nebulosa",

${ }^{19}$ Nesta revista, editada entre os anos de 1850 e 1855, apareceu grande parte do seu poemaromance "A nebulosa", que alguns críticos consideram um dos melhores do Romantismo. A revista contribuiu para a consolidação do intuito maior do projeto romântico que era o de criar uma identidade nacional brasileira, além de toda a gama temática da primeira geração de poetas (BLAKE, 1970). 
publicado por Macedo em 1857. Macedo respondia escrevendo crônicas chamadas "O Labirinto", no Jornal do Commercio.

Nesse jornal, entre janeiro de 1861 e fevereiro de 1862, Macedo redigiu inúmeras crônicas, consolidando a coluna denominada "Crônica da Semana".

Sua experiência docente, aliada a sua preocupação pedagógica, orientou sua produção de livros para o ensino de História do Brasil. Nesse movimento intelectual, o professor autor constrói os fundamentos de uma disciplina escolar e de uma pedagogia histórica - na articulação do conteúdo histórico com o método de ensino. Seu texto didático já nasce endereçado a estes dois grupos de leitores específicos: aos alunos - ensina o que estudar; e ao professor - o que e como ensinar.

Nos últimos anos, algumas pesquisas têm trazido contribuições para o estudo da obra didática de Macedo, como em Mattos (2000) e no estudo de Gasparello (2004) que analisou o discurso da nação nos livros didáticos do século XIX e início do XX - dentre os quais os livros de Joaquim Manuel de Macedo, este considerado como o fundador, nos livros didáticos, da fase de uma "história imperial", segundo os princípios orientadores do Instituto Histórico e Geográfico Brasileiro (IHGB) e da obra de Varnhagen (1854).

A publicação do primeiro volume da História geral do Brasil, em 1854, ${ }^{20}$ marcou o início da produção historiográfica brasileira segundo critérios metodológicos modernos, associados aos princípios de uma história metódica com base em fontes documentais. Sua obra tornou-se o referencial maior na elaboração de livros didáticos que serviram à divulgação da história da nação segundo os parâmetros monarquistas da elite no poder e das instituições que respaldavam esse modelo, como o IHGB e o Colégio de Pedro II. Começaram então a ser delineadas, no círculo de intelectuais ligados ao Instituto, duas importantes funções que, embora diferenciadas em método e objetivos, complementavam-se na perspectiva dos fins a que estavam associadas, voltados para a construção de uma identidade brasileira fundamentada em uma interpretação do nosso passado colonial. Na elaboração da história oficial, legitimada socialmente, exerceram o seu papel: o historiador - sem adjetivos - e o historiador didático - que escrevia livros de História para o ensino. A História geral do Brasil do historiador reconhecido pelo IHGB forneceu, além de uma concepção historiográfica moderna, um roteiro para o discurso da nação identificada com o Império.

\footnotetext{
${ }^{20}$ Foi publicada em Madri, onde se encontrava o historiador; o segundo e último volume veio a público em 1857 (GARCIA, 1928).
} 
Desde 1840, o Instituto tivera a iniciativa de conceder um prêmio a quem apresentasse o melhor plano de como escrever a história do Brasil. Coube ao naturalista alemão Karl Friedrich Philip von Martius, uma das maiores expressões da cultura europeia, ${ }^{21}$ obter o prêmio com sua monografia, publicada pelo Instituto em 1845, antes mesmo da divulgação do resultado do concurso. ${ }^{22}$

Martius tornou-se uma figura importante na história da cultura brasileira. Como naturalista, lançou as bases da botânica brasileira e sua memória Como se deve escrever a história do Brasil repercutiu significativamente na nossa historiografia. Para Iglésias (2000), o naturalista, ao levantar as grandes linhas da história do Brasil, revela uma fina sensibilidade de historiador. Lacombe (2000), em A importância da obra de Martius para a historiografia brasileira, ressalta ter sido Martius o primeiro a indicar a importância do negro e do índio na formação do espírito brasileiro.

Martius (1991, p. 54) termina sua monografia com a defesa de uma história em favor da pátria:

Uma obra histórica sobre o Brasil deve [...] despertar e reanimar em seus leitores brasileiros amor da pátria, coragem, constância, indústria, fidelidade, prudência, em uma palavra, todas as virtudes cívicas.

O modelo de pátria a ser reforçado seria o do Império, com a unidade das províncias junto à Monarquia, para convencer os republicanos de todos os matizes e a todos os brasileiros das inconveniências dos "projetos utópicos", das "discussões licenciosas sobre os negócios públicos, por uma imprensa desenfreada, e da necessidade de uma Monarquia em um país onde há um tão grande número de escravos" (p. 54). Na visão do historiador como um agente do Estado, com a missão de fortalecer o vínculo entre monarquia e nação brasileira, resume:

Nunca esqueça, pois, o historiador do Brasil, que para prestar um verdadeiro serviço à sua pátria deverá escrever como autor monárquico-constitucional, como unitário no mais puro sentido da palavra (p. 55, grifos nossos).

A memória premiada de Martius distingue-se por ser a primeira a propor questões e a teorizar sobre a história do Brasil, quando o comum da historiogra-

${ }^{21}$ Martius veio ao Brasil em 1817, em missão científica, junto com J. von Spix, que resultou na descrição de milhares de espécies na monumental obra Flora Brasiliensis. Escreveram também Viagem pelo Brasil, publicado pelo IHGB em 1838 (IGLÉSIAS, 2000).

${ }^{22}$ A segunda edição foi em 1943, pela Revista do IHGB, v. 219; em 1991, foi publicada a primeira edição em livro, pelo IHGB, na Coleção Capistrano de Abreu. 
fia nativa era a crônica de mera descrição, sem qualquer problemática (Iglésias, 2000). Por isto mesmo, seu trabalho foi considerado como de nível superior às possibilidades do momento no Brasil. ${ }^{23}$ Mas seu plano conquistou um lugar de destaque na nossa historiografia, ao conseguir realizar sua finalidade, como fonte de inspiração e fundamento para futuros historiadores mesmo sem concordar com todos os princípios levantados pelo cientista (Glénisson, 1983) ${ }^{24}$ A circunstância especial da formação de "um povo novo", nascido da "reunião e do contato de tão diferentes raças humanas" é destacada pelo autor no primeiro capítulo (Martius, 1991, p. 30). ${ }^{25}$ Orienta, então, que o historiador deverá ser "reflexivo", segundo os princípios de uma história filosófica e pragmática, para não perder de vista "os elementos que aí concorreram para o desenvolvimento do homem". Apesar de seguir as concepções de seu tempo sobre a existência de "raças superiores" e "inferiores", não demonstra uma visão pessimista da miscigenação. Para ele, o historiador deveria colocar-se acima de visões parciais ou "odiosas" e confiar na "perfectibilidade de uma parte do gênero humano" (Martius, 1991, p. 33).

A instituição abrira a discussão e Martius fornecera um modelo para os historiadores; e com a História geral do Brasil, de Francisco Adolfo de Varnhagen (1854), membro do Instituto e reconhecido por seus trabalhos de pesquisa, apresentou-se uma conjuntura favorável ao desenvolvimento historiográfico, com repercussão nos livros didáticos e no ensino.

Varnhagen destacou-se também como autor erudito, "talvez o mais completo até hoje" no Brasil, com dezenas de publicações no campo historiográfico (Iglésias, 2000, p. 74). ${ }^{26}$ A História geral resultara de anos de pesquisa e materializara seu propósito antigo de escrever a nossa história, cujos estudos preliminares na Europa haviam resultado nas Reflexões e no Diário de Pero Lopes, no tempo em que, no Brasil, o Instituto Histórico iniciava sua trajetória institucional.

\footnotetext{
${ }^{23}$ Sobre os argumentos do plano de Martius ser de difícil execução naquele momento, ver GUIMARÃES, 1995.

${ }^{24}$ Foi o caso de João Ribeiro (1900) que, 60 anos depois, afirma seguir as propostas de Martius mas não concorda, no texto sobre os mestiços, com sua teoria sobre a perfectibilidade das raças inferiores (Ver GASPARELLO, 2004).

${ }^{25}$ O sábio alemão, juntamente com Paul Erhreich e Karl van den Steinen é considerado um dos fundadores da etnologia brasileira. (Ver GARCIA, Nilo. Notas e comentários. In: MARTIUS, 1991, p. 58).

${ }^{26}$ Seus textos principais, além da História geral, foram a História das lutas com os holandeses no Brasil, desde 1624 a 1654, de 1872, e História da Independência do Brasil, de 1874, cuja preparação anunciou no final da segunda edição da História geral, e que deixou por terminar. Anotada pelo barão do Rio Branco e Basílio de Magalhães, foi publicada em 1916 na Revista do IHGB, tomo 79 (GARCIA, 1928).
} 
A crítica historiográfica à História geral de Varnhagen ressalta a abordagem cronológica e estática do processo histórico:

Segue mais a cronologia que a temática; a intitulação dos capítulos é inexpressiva, pois mais esconde que revela as novidades que contém. Porque é mais cronológica que temática, na concepção geral, é também expressão de um processo construtivo mais estático que dinâmico... O grande tema é a obra da colonização portuguesa no Brasil (Rodrigues, 1970, p. 128).

A orientação discursiva é de exaltação à monarquia e de culto à ordem, com a oposição a todos os movimentos de contestação à autoridade instituída. Ao contrário, condenava os princípios democráticos republicanos e demonstrava horror a todo inconformismo, o que o levava a considerar anarquistas os movimentos mais exaltados. Além disso, seu discurso é de justificação e defesa da escravidão negra e da ação autoritária em relação aos índios. Rodrigues (1970, p. 130) aponta que o autor expressa preconceitos políticos, sociais, religiosos, "especialmente no julgamento das figuras e no tratamento dos inconformismos".

Com essa perspectiva, a História geral fundamentou uma "história oficial" que se tornou a "história tradicional" de longa duração nos livros didáticos. Aquele momento da produção de compêndios de história do Brasil para o ensino secundário caracterizou-se por corresponder, no ensino, ao projeto de nação legitimado por uma instituição - o Instituto Histórico e Geográfico Brasileiro (IHGB) ${ }^{27}$, e identificado a uma obra - a História geral do Brasil, de Varnhagen (1854).

A publicação de Lições dá início à fase de legitimação do modelo nacional na historiografia didática imperial, cujos compêndios indicavam o Imperial Colégio de Pedro II como referência maior: lugar social do autor, como professor de História e o dos destinatários - "para uso dos alunos do Imperial Colégio".

A obra erudita de Varnhagen (1854) e a obra didática de Macedo (1861), além da primeira ter sido referência para a segunda, nasceram ligadas pelo lugar social, de maior amplitude, a que pertenciam os seus autores:

Herdeiro de uma tradição marcadamente iluminista e vivenciado como tal por seus membros, o Instituto propõe-se a levar a cabo um projeto dos novos tempos, cuja marca é a soberania do princípio nacional enquanto critério fundamental definidor de uma identidade social (Guimarães, 1988, p. 7).

${ }^{27}$ A contribuição do IHGB aos estudos históricos e geográficos é analisada em diversos estudos que o articulam ao projeto de pensar a história brasileira de forma sistematizada e ao processo de consolidação do Estado-nação (GUIMARÃES, 1988; GUIMARÃES, 1995). 
Após as Lições de Macedo os livros adotados para o ensino de História do Brasil foram, em sua maioria, aqueles cujos autores eram também professores da instituição. ${ }^{28}$

No prefácio das Lições, Macedo (1861) explicita sua concepção sobre a necessidade de um ensino que leve em conta a compreensão do que estava sendo memorizado. A pedagogia da memória, do saber "de cor" continua na proposta macediana, mas o autor distingue entre decorar sem nexo e compreender o que está sendo memorizado:

[...] Um menino que tem decorado uma lição nem por isso sabe a lição; para que a saiba é indispensável que compreenda o que exprimem, o que significam as palavras que repete de cor; por esta razão anexamos no nosso compêndio a cada lição algumas explicações, que o professor deve completar ajuntando a essas tantas outras quantas forem necessárias.

Resumia esse método em passos necessários à aprendizagem e eram destacados como explicações, perguntas e quadros sinóticos anexos às "lições". Nesses, eram indicados os "personagens", "atributos", "feitos" e "acontecimentos".

\section{Explicações}

A seção das "Explicações", ao final de cada lição, apresentava o significado dos conceitos e outros termos que o autor considerava necessário para auxiliar a aprendizagem histórica do aluno. A formatação dessas explicações era impressa em fonte bem menor do que a fonte utilizada para a exposição do texto da "lição".

Tais inovações constituem saberes pedagógicos e tecnologias educacionais que foram incorporados aos livros didáticos dos professores/autores sensibilizados com as questões do seu tempo, como Gasparello (2004, p. 133) chamou a atenção:

As discussões sobre ensino no final do século XIX e início do século XX centralizavam no professor e na necessidade de método os problemas do ensino e, neste aspecto, Macedo é também expressão das preocupações da época sobre o ensino, ao contribuir na construção de uma pedagogia para o ensino de História.

${ }^{28}$ Os autores dos primeiros livros adotados para o ensino de história nacional no Colégio e que não pertenciam à instituição foram os seguintes: Resumo de Historia do Brasil até 1828, traduzido de mr. Denis, correcto e augmentado por H. L. de Niemeyer Bellegarde. Rio de Janeiro: Typ. Gueffier, 1831; e LIMA, José Ignácio de Abreu e. Compendio da Historia do Brasil. Tomos I e II. Rio de Janeiro: Eduardo e Henrique Laemmert, 1843. Tais livros correspondem ao primeiro momento da historiografia didática para o ensino de história nacional, denominada "fase patriótica" (Sobre o tema, cf. GASPARELLO, 2004). 
Em "Explicações", pode-se ler o que o autor considerou necessário para auxiliar a aprendizagem histórica do aluno. Os termos fornecem esclarecimentos de cunho geográfico e de cunho linguístico. Muitas vezes aparecem na forma de dicionário: "Cosmografia é a sciencia que se ocupa da descrição do universo, e universo é a totalidade das cousas creadas".

\section{Perguntas}

As perguntas são dispostas sem numeração e tendem a privilegiar os acontecimentos e personagens da história narrada no texto da "lição". Tinham como finalidade auxiliar o professor, com a indicação do que deveria ser enfatizado no ensino de História, e ao aluno, visava fornecer um caminho para facilitar a memorização da relação entre as personagens, os acontecimentos e as datas.

As perguntas seguem esse padrão de indagação: quem, onde, quando, por que, o que, qual... Exemplos: "Por que Portugal causou admiração ao mundo no século décimo quinto?" "Que plano concebera o infante D. Henrique, plano que não realizou por um grande 'infortuito' que sobreveio a Portugal a 13 de novembro de 1460 ?"

Em seu livro didático, Macedo (1861) expõe as bases de um método de ensino para ser seguido pelos professores e alunos. A preocupação pedagógica resultava da experiência docente: seu método tinha por objetivo facilitar a docência e a aprendizagem em História. Suas orientações didáticas caracterizam-se como ações instituintes no campo pedagógico da história ensinada, levando-se em conta que as publicações específicas sobre metodologia do ensino de História só apareceram mais de cinquenta anos depois dessa obra, com Methodologia da História na aula primária em 1917, e Como se ensina história em 1935, que tiveram como autor o então professor de História do Colégio, Jonathas Serrano. ${ }^{29}$

O texto didático macediano constitui um exemplo de processo de transformação de saberes em conhecimento escolar chamado de transposição didática. ${ }^{30}$ Na sua função autor, tornou pública uma história nacional e orientou um método para o ensino e a aprendizagem em História. Não escreveu um guia metodoló-

${ }^{29}$ A Methodologia da História na aula primária foi publicada no Rio de Janeiro pela Francisco Alves em 1917 e Como se ensina história em São Paulo, pela Melhoramentos, em 1935, segundo os princípios da chamada "escola nova" (Cf. FREITAS, 2006).

${ }^{30}$ Conceito desenvolvido por Chevallard (1991), que contribuiu para o debate sobre os processos históricos associados à formação das disciplinas escolares, estas percebidas como resultantes de uma complexa transformação de saberes externos e internos à escola em saberes escolares (Cf. LOPES, 1999; GABRIEL, 2001). 
gico, mas seu livro didático abrange a lição de história e um método de ensino. Representa uma ação inovadora na configuração de uma disciplina escolar e sua pedagogia: a palavra compreensão passa para o vocabulário do texto didático, inaugurando uma mudança substancial na relação aluno-conhecimento escolar, até aqui visto como um processo de recepção passiva, com base nas noções de aprendizagem como simples apropriação memorizada dos textos.

Nosso estudo aproxima-se da concepção de que precisamos pensar o ensino em sua própria história e no reconhecimento da autonomia relativa do campo escolar em face do campo político ou científico. Implica reconhecer que a história do ensino envolveu uma recriação permanente da cultura de uma sociedade, "esta recriação permanente e coletiva sendo obra específica de alunos e professores, com seus dispositivos pedagógicos próprios” (Cuesta Fernández, 1997, p. 33).

\section{Considerações finais}

Nesse período, a produção de livros didáticos teve, por autores, intelectuais de projeção na vida política e cultural da cidade e a contribuição de Joaquim Manuel de Macedo na historiografia didática foi situada no interior do grupo específico de intelectuais que se caracterizavam por suas atividades docentes e literárias.

As ações instituintes desse autor na escrita de uma história escolar brasileira deixaram marcas na história do livro didático e do ensino. Seu método tinha por objetivo facilitar a docência e a aprendizagem em História, o que pode ser visto como uma ação instituinte no campo pedagógico. Não escreveu um guia metodológico, mas seu livro didático representou uma ação inovadora na constituição de uma disciplina escolar e sua pedagogia: a palavra compreensão passa para o vocabulário do texto didático, inaugurando uma mudança substancial na relação do aluno com os saberes escolares, até aqui vista como uma recepção passiva e na perspectiva de cultura como acumulação de textos memorizados.

Como intelectual/professor, Macedo participou ativamente da experiência histórica de sua contemporaneidade, quando a necessidade de livros didáticos para o ensino encontrou no meio dos letrados que atuavam no magistério uma resposta assumida a partir da função professor que exerciam. Uma função desdobrada em uma autoria: a escrita de uma palavra que se inscreveu inicialmente em outro lugar - a sala de aula.

Encontramos em Macedo uma trajetória e um pertencimento a uma "identidade comum" e a um "espaço intelectual", o que lhe conferiu historicidade, um vínculo ao seu tempo - monarquista e de justificação de uma história da nação imperial. Mas uma trajetória também profundamente marcada por sua 
individualidade de intelectual e professor/autor: a preocupação com o ensino e um método para aprender história.

\section{Referências bibliográficas}

ALMEIDA, José Ricardo Pires de. História da instrução pública no Brasil (1500-1889). Tradução de Antonio Chizzotti. São Paulo: Educ; Brasília, DF: Inep/MEC, 1989.

ANDRADE, Vera Lúcia Cabana de Queiroz. Colégio Pedro II. Um lugar de memória. Tese de doutorado. Programa de Pós-Graduação em História Social do Instituto de Filosofia e Ciências Humanas da Universidade Federal do Rio de Janeiro, 1999. BESSONE, Tânia Maria. Palácios de destinos cruzados: bibliotecas, homens e livros no Rio de Janeiro, 1870-1920. Rio de Janeiro: Arquivo Nacional, 1999.

BITTENCOURT, Circe Maria Fernandes. Livro didático e saber escolar (1810-1910). Belo Horizonte: Autêntica, 2009.

BLAKE Sacramento. Diccionario bibliographico brazileiro. Rio de Janeiro: Conselho Federal de Cultura, 1970.

CARVALHO, José Murilo de. A construção da ordem: a elite política imperial. Rio de Janeiro: Civilização Brasileira, 2003.

CARVALHO, José Murilo de. Teatro de sombras: a política imperial. Rio de Janeiro: Civilização Brasileira, 2003.

CHARTIER, Roger. Textos, impressão, leitura. In: HUNT, Lynn (org.). A nova história cultural. Tradução de Jefferson Luiz Camargo. São Paulo: Martins Fontes, 1992.

CHARTIER, Roger. A ordem dos livros: leitores, autores e bibliotecas na Europa entre os séculos XIV e XVIII. Tradução de Mary del Priore. Brasília: Universidade de Brasília, 1994.

CHEVALLARD, Y. La transposition didactique: du savoir savant au savoir enseigné. Grenoble: La Pensée Sauvage Éditions, 1991.

CHOPPIN, Alain. Le manuel scolaire en cent références. Paris: Institut National de Recherche Pédagogique, 1991.

CHOPPIN, Alain (dir.). Les manuels scolaires: histoire et actualité. Paris: Hachette Éducatión, 1992.

CHOPPIN, Alain. História dos livros e das edições didáticas: sobre o estado da arte. Educação e Pesquisa. São Paulo, v. 30, n. 3, set./dez. 2004, p. 549-566.

CUESTA FERNÁNDEZ, Raimundo. Sociogénesis de uma disciplina escolar: la Historia. Barcelona: Ediciones Pomares-Corredor, 1997. Colección Educación y Conocimiento.

DARNTON, Robert. O beijo de Lamourette: mídia, cultura e revolução. Tradução de Denise Bottmann. São Paulo: Companhia das Letras, 1990.

DORIA, Escragnolle. Memória histórica do Colégio de Pedro Segundo (1837-1937). $2^{\text {a }}$ ed. Brasília: Inep, 1997. 
DOSSE, François. O império do sentido: a humanização das ciências humanas. Tradução de Ilka Stern Cohen. Bauru, SP: Edusc, 2003.

EDMUNDO, Luiz. O Rio de Janeiro do meu tempo. Rio de Janeiro: Imprensa Nacional, 1938.

FORQUIN, Jean-Claude. Escola e cultura: as bases sociais e epistemológicas do conhecimento escolar. Tradução de Guacira Lopes Louro. Porto Alegre: Artes Médicas, 1993.

FOUCAULT, Michel. O que é um autor? $3^{\mathrm{a}}$. ed. Tradução de António Fernandes Cascais e Eduardo Cordeiro. Portugal: Veja, 1992.

FREITAS, Itamar. A pedagogia da história de Jonathas Serrano para o ensino secundário brasileiro (1913/1935). Tese de doutorado em Educação. Pontifícia Universidade Católica de São Paulo. São Paulo, 2006. 378 p.

GABRIEL, Carmen Teresa. Usos e abusos do conceito de transposição didática considerações a partir do campo disciplinar de História. SEMINÁRIO PERSPECTIVAS DO ENSINO DE HISTÓRIA 4. Anais. Ouro Preto, 2001, p.1-7. Disponível em www.ichs.ufop.br/perspectivas/anais/GT0509.htm

GARCIA, Nilo. Notas e comentários. In: MARTIUS, Karl Friedrich von. Como se deve escrever a história do Brasil. 1. ed. em livro. Rio de Janeiro: IHGB, 1991, p. 58.

GARCIA, Rodolfo. Varnhagen (annexo à ata da sessão de 6 de julho de 1928). Revista. IHGB, vol. 158, t. 104, 1928, p. 996-1.021.

GASPARELLO, Arlette M. Construtores de identidades: a pedagogia da nação na escola secundária brasileira. São Paulo: Iglu, 2004.

GASPARELLO, Arlette M. Os professores e seu ofício: ensinar, escrever e fazer história. XXIII SIMPÓSIO NACIONAL DAASSOCIAÇÃO DE PROFESSORES DE HISTÓRIA. Anais. Londrina: ANPUH, 2005, CD-ROM.

GASPARELLO, Arlette M.; VILLELA, Heloisa de O. S. Intelectuais e professores: identidades sociais em formação no século XIX brasileiro. Revista Brasileira de História da Educação. Campinas/SP, SBHE, Ed. Autores Associados, nº 21 , set./dez./2009, p. 39-60.

GLÉNISSON, Jean. Iniciação aos estudos históricos. 4. ed. São Paulo: Difel, 1983.

GOODSON, Ivor F. Currículo: Teoria e História. Tradução de Attílio Brunetta. Apresentação de Tomaz Tadeu da Silva. Petrópolis, RJ: Vozes, 1995.

GUIMARÃES, Lúcia Maria Paschoal. Debaixo da imediata proteção imperial: o Instituto Histórico e Geográfico Brasileiro (1838-1889). Revista do Instituto Histórico e Geográfico Brasileiro. Rio de Janeiro, a. 156, n. 388, jul./set./1995, p. 459-613.

GUIMARÃES, Manoel Luís Salgado. Nação e civilização nos trópicos: o Instituto Histórico e Geográfico Brasileiro e o projeto de uma história nacional. Estudos Históricos. Rio de Janeiro, n. 1, 1988, p. 5-27.

HAIDAR, Maria de L. M. O ensino secundário no império brasileiro. São Paulo: Edusp/ Grijalbo, 1972. 
HALLEWELL, Laurence. O livro no Brasil (sua história). São Paulo: T. A. Queirós/ Edusp, 1985.

HERY, Evelyne. Un siècle de leçons d'histoire. L'histoire ensegnée em lycée de 1870 à 1970. Rennes: Presses Universitaires de Rennes, 1999.

IGLÉSIAS, Francisco. Os historiadores do Brasil: capitulos de historiografia brasileira. Rio de Janeiro: Nova Fronteira; Belo Horizonte, MG: UFMG, Ipea, 2000.

KOSELLECK, Reinhart. Uma história dos conceitos: problemas teóricos e práticos. Estudos Históricos, Rio de Janeiro, vol. 5, n. 10, 1992, p. 134-146.

KOSELLECK, Reinhart. Futuro passado: contribuição à semântica dos tempos históricos. Tradução de Wilma Patrícia Maas e Carlos Almeida Pereira. Rio de Janeiro: Contraponto; Ed. PUC-Rio, 2006.

LEITE, Serafim. S. I. História da Companhia de Jesus no Brasil. Tomo VII. Belo Horizonte-Rio de Janeiro: Itatiaia, 2000.

LOPES, Alice Casimiro. Conhecimento escolar: ciência e cotidiano. Rio de Janeiro: Editora da UERJ, 1999.

LOPES, Marcos Antônio. (org.). Grandes nomes da história intelectual. São Paulo: Contexto, 2003.

MAGALHÃES, Manuel Luís Salgado. 1988. Nação e civilização nos trópicos: o Instituto Histórico e Geográfico Brasileiro e o projeto de uma história nacional. Estudos Históricos. Caminhos da historiografia. Rio de Janeiro, n. 1, Cpdoc/FGV, p. 5-27.

MACEDO, Joaquim Manuel de. Lições de Historia do Brazil para uso dos alumnos do Imperial Collegio de Pedro Segundo. Rio de Janeiro: Typ Imparcial, de J. M. N. Garcia, 1861. 143 p.

MACEDO, Joaquim Manuel de. Lições de História do Brasil para uso dos alumnos do Imperial Collegio de Pedro Segundo por Joaquim Manoel de Macedo. Professor de Chorographia e Historia do Brasil no mesmo Collegio. Rio de Janeiro: Domingos José Gomes Brandão, 1863. 300 p.

MARTIUS, Karl Friedrich von. Como se deve escrever a história do Brasil. 1. ${ }^{a}$ ed. em livro. Rio de Janeiro: IHGB, 1991. Coleção Capistrano de Abreu.

MARLETTI, Carlo. Intelectuais. In: BOBBIO, Norbert; MATTEUCCI, Nicola; PASQUINO, Gianfranco. (orgs.). Dicionário de política. Tradução de Carmen C. Varriale et al. 5. ed. Brasília: Editora da Universidade de Brasília, 1993, vol. 01.

MATTOS, Selma Rinaldi. O Brasil em lições: a história como disciplina escolar em Joaquim Manuel de Macedo. Rio de Janeiro: Access, 2000.

MOREL, Marco. Sociabilidades entre luzes e sombras: apontamentos para o estudo histórico das maçonarias da primeira metade do século XIX. Estudos Históricos. Rio de Janeiro, n. 28, 2001.

MOSCATELI, Renato. História intelectual: a problemática da interpretação de textos. In: LOPES, Marcos Antônio (org.). Grandes nomes da história intelectual. São Paulo: Contexto, 2003, p. 48-59. 
PROST, Antoine. Doze lições sobre a história. Tradução de Guilherme João de Freitas Teixeira. Belo Horizonte: Autêntica Editora, 2008.

RAMOS, César Augusto Ornellas. Noticia bibliográfica de Joaquim Manuel de Macedo (1820-1882). Itaboraí, 2004.

RODRIGUES, José Honório. História e historiografia. Petrópolis, Rio de Janeiro: Vozes Ltda., 1970.

SILVA, Geraldo Bastos. Introdução crítica ao ensino secundário. Rio de Janeiro: MEC/Cades, 1959.

SILVA, Geraldo Bastos. A educação secundária: perspectiva histórica e teoria. São Paulo: Nacional, 1969.

SIRINELLI, Jean-François. Os intelectuais. In: RÉMOND, René (org.). Por uma história política. Tradução de Dora Rocha. Rio de Janeiro: Editora UFRJ, 1996, p. 231-269.

VARNHAGEN Francisco Adolpho de. Historia geral do Brasil. Madrid: Imprensa da V. Domingues, 1854.

Recebido: 23/07/2010 - Aprovado: 26/01/2011 